\title{
Nurses’ Perceptions of Nurse Manager Leadership Styles
}

\author{
Bander Albagawi*, Vivian Laput, Carmencita Pacis, Tahani AlMahmoud \\ Nursing Administration, Hail University, Hail, KSA \\ *Corresponding author: saad1510@hotmail.com
}

\begin{abstract}
Leaders are in best position to facilitate the changes because they are considered as change agents. Transformational leadership is defined as a leadership approach that causes changes in individuals and social systems. The purpose of this study was to determine leadership styles of nurse managers and their outcomes in government hospitals in Hail City (Saudi Arabia). The study respondents were head nurses and nurses working in 4 government hospitals. The Multifactor Leadership Questionnaire was used to measure nurse manager leadership styles as perceived by nurses and the nurse managers themselves. There were no significant differences between the perceived leadership styles of the nurse managers themselves and the perception of the nurses on the nurse managers' leadership styles $(\mathrm{P}=0.719)$. When determining whether there was a significant association between the perceived leadership styles of the nurse managers and the outcomes of that leadership, the results yielded a significant (moderate) relationship between a transformational leadership style and the outcomes of leadership in terms of extra effort $(\mathrm{P}=0.000)$, effectiveness $(\mathrm{P}=0.000)$, and satisfaction $(\mathrm{P}=0.000)$.
\end{abstract}

Keywords: leadership, nursing, Saudi Arabia, Multifactor Leadership Questionnaire, transformational leadership style

Cite This Article: Bander Albagawi, Vivian Laput, Carmencita Pacis, and Tahani AlMahmoud, "Nurses' Perceptions of Nurse Manager Leadership Styles.” American Journal of Nursing Research, vol. 5, no. 1 (2017): 22-31. doi: 10.12691/ajnr-5-1-3.

\section{Introduction}

Nursing is a demanding job. The role of nurses is one that has been regarded as stressful because it requires physical labor, engenders strong emotions to witnessing human suffering, and long hours of standing during work. It also involves problems in staffing and in dealing with interpersonal and cultural diversity, and stress caused by the increasing demands for nurses to adapt to the evergrowing advances in technology being utilized in health care, continuing rises in health care costs, and turbulence within the work environment [1].

Nurse leaders of today face challenges that focus not any more on the process of how care is delivered, but on the outcomes of care. Emphasis is on the standard provision of care that must be proven with proper documentation. There is also the focus on reporting of patient satisfaction, thus make the nurse leaders realize the weights of explicit accountability for managing and leading the staff responsible for providing the quality patient care [2].

Several authors have emphasized the importance of effective leadership in health care. Nursing leadership is pivotal because nurses represent the largest discipline in health care $[3,4,5,6,7]$. The present key challenge face by health care services organizations worldwide is to nurture an organizational culture that ensures the delivery of continuously improving high quality, safe, and compassionate health care. Leadership is the most influential factor in shaping organizational culture, and in ensuring that the necessary leadership behaviors, strategies, and qualities are developed. There is a compelling and urgent need for clinical governance which is considered a robust framework that acknowledges the importance of adopting a culture of shared accountability for sustaining and improving the quality of services and outcomes for both patients and staff [8].

Health care leadership must go beyond boundaries within and across any health care organization. Thus, working together as an organizational entity, leaders must manifest influencing, and empowering behaviors through effective communications in order to share and learn from and with each other in practice [9].

In Saudi Arabia, where the Saudization movement began in 2011, the nursing service is still facing an ongoing shortage of Saudi-born nurses, and especially Saudi-born nurse managers. The rapid turnover of nurses and nurse managers in our country has brought about challenges in the health care system, risking a crisis such as the one that occurred during the Gulf war in 1990 [10,11].

Nurse leaders must help their staff navigate complex health care reform laws and keep patients satisfied with their care, while also keeping costs as low as possible and predicting the future needs of this rapidly changing industry. Numerous studies have shown that positively proactive leaders who lead by example are perceived as being more effective leaders, and staffs perform for them better [12,13,14,15,16,17]. Leadership models abound, and many have been adapted to health care settings $[18,19,20,21]$. A competent and strong leadership is essential for the achievement of organizational goals. Thus, 
given the current nursing shortage in Saudi Arabia, it is important to reexamine the leadership styles of our nurse managers and the perceptions of their subordinates to determine which leadership styles could produce the most effective outcomes.

Leadership is defined as a process whereby an individual influences a group of other individuals to achieve a common goal. Because leaders and followers are both part of this process, it is important to address those issues that confront followers as also being issues that confront leaders. Leaders and followers should be understood in relation to each other [22].

Innovative leadership models and theories are salient in addressing the core competencies of contemporary nursing management, which are congruous with the needs of professional nursing practice and a consumer-responsive society [23]. Empirical research and theoretical literature offer many leadership styles. However, the merits of transformational leadership are gathering momentum because this style challenges the autocratic unilateral leadership models of former years. As with each leadership style, transformational leadership necessitates numerous attributes and conditions to effect its qualities successfully.

In a study of nursing leadership in Saudi Arabia, it has been found that leadership is more effective with a transformational approach. Researchers have found hospital leadership to be an influential factor in job satisfaction by their subordinates [24,25]. Research suggests that when hospital leadership encourages subordinate empowerment there is a direct link to increased subordinate job satisfaction and motivation [26]. Evidence has shown that empowered nurses shift their self-perceived role from being a subordinate to that of a collaborator. This encourages consensus building, improves job ownership, and improves trust and the follower's motivation, sense of responsibility and organizational commitment [27,28].

Reference [29] Bass and Avolio's (1994) theory of transformational leadership served as the theoretical framework for this research study. Their theory has been widely used to determine the most effective leadership styles. They concluded that transformational leaders have the greatest positive effect on followers, compared with transactional or passive/avoidant leaders. First developed by Burns for political leaders, Bass and Avolio adapted the transformational theory for business organizations and created the Multifactor Leadership Questionnaire (MLQ) Form $5 X$ to quantify leadership styles. Using the MLQ Form 5X, Bass and Avolio defined leaders as transformational, transactional, or passive/avoidant. However, they stated that the most effective leaders were not truly transformational but also exhibited transactional qualities where necessary. Burns (1978) introduced this concept more completely in his book Leadership. Burns was highly inspired by Maslow's Theory of Human Needs [30]. In 1985, Bass, a disciple of Burns, further developed the concept of transformational leadership by explaining the psychological mechanisms that underlie transforming and transactional leadership; Bass also used the term "transformational" instead of "transforming." Bass added to the initial concepts of Burns (1978) to help explain how transformational leadership could be measured, as well as how it impacts follower motivation and performance. Specifically, he suggested that transformational leaders should try to transform their followers by raising their awareness regarding task outcomes, and by encouraging them to transcend their own self-interest for the interest of the organization, as well as activating their higher order needs. By grouping certain leadership traits, Bass identified three basic types of leadership style: transactional, transformational, and laissez-faire (or inactive). The transactional type specifies tasks, monitors performance, and seeks to achieve the desired outcome by providing a reward system. Transformational leadership aims to motivate employees by inspiring them and providing them with individual attention, while also stimulating their intellectual needs. The third type, laissez-faire leadership, involves remaining aloof from the responsibilities of leadership, instead leading from a distance [29].

\section{Methods}

The purpose of this study was to determine the leadership styles of the nurse managers and their outcomes in four government-based hospitals in Hail City.

Specific research questions to be addressed were as follows.

1. Define the profiles of nurse managers and staff nurses in terms of:
a. Age
b. Gender
c. Nationality
d. Educational attainment
e. Hospital location
f. Years of experience
g. Trainings attended
h. Salary

2. Define the leadership styles of nurse managers as perceived by:

a. Staff nurses

b. Nurse managers themselves

3. Is there a significant difference in the perceived leadership styles of the nurse managers when they are grouped according to their profile?

4. Is there a significant difference in the perception of the staff nurses on the nurse managers' leadership style when they are grouped according to their profile?

5. Is there a significant difference in the perceptions of leadership styles of the nurse managers between the staff nurses and the nurse managers themselves?

6 . What are the outcomes of the nurse managers' leadership styles as perceived by the subordinates (staff nurses) in terms of:
a. Extra effort
b. Effectiveness
c. Satisfaction

7. Is there a significant relationship between the perceived leadership styles of the nurse managers and the outcomes of their leadership?

\subsection{Ethical Considerations}

Before the study, approval was obtained from an Ethics Committee in the University of Hail (EC\#173), official permission was obtained from the Department of Health Affairs in Hail region, and written informed consent was 
obtained from all participants. Moreover, participants who completed the questionnaire survey also filled out an informed consent form agreeing to participate in the study. Study participants were briefed on the study purpose and process, as well as their right to withdraw participation at any time without any adverse effect on their employment status. In this research project, we conform to the provisions of the Declaration of Helsinki in 1995 (as revised in Brazil 2013) [31].

\section{Results}

\subsection{Data Analysis}

After data were collected, the questionnaires were checked for the completeness and consistency of responses. Analysis was performed using IBM Statistical Packages for the Social Sciences (SPSS) Statistics 20 software. The results were analyzed using descriptive statistics such as frequency distributions and percentages to determine the demographic profile of the respondents and inferential statistics such as Student's t test, one-way Analysis of Variance (ANOVA) and Pearson productmoment correlation to establish if there is difference or relationship among and between variables.

1. Result shows that most of the nurse managers and staff nurses are aged between 20 - 30 years of age who were females that are Saudi Nationals. A lot finished their Bachelor's degree only were a bulk of the nurse managers came from Maternity Hospital and staff nurses from King Khalid Hospital. Majority of the respondents served the hospital less than 10 years and most don't attend trainings.

2. The identified leadership styles of nurse managers fairly often displayed transformational leadership (3.03) sometimes of transactional leadership (2.22) and laissezfaire once in a while with (1.05). On the other hand, staff nurses believed that they are managed by their superiors utilizing transformational leadership style (2.85) which is ranked first and seconded by transactional leadership (2.30). Further, results also reveal that Laissez-faire leadership is employed by their superiors only once in a while as evaluated by the respondents (1.38).

3. There is a significant difference noted in the perceived leadership styles of the nurse managers when grouped according to hospital they were connected $(\rho=0.005)$; nationality $(\rho=0.002)$ and in terms of their salary $(\rho=0.004)$. However, there is no significant difference in their perceived leadership style when they are clustered according to their educational attainment $(\rho=0.232)$; gender $(\rho=0.292)$; age $(\rho=0.851)$; years of experience $(\rho=0.533)$; and on the trainings they attended $(\rho=0.484)$.

4. There is a significant difference in the perception of the staff nurses on their nurse managers' leadership styles when they are group according to salary received $(\rho=0.005)$. On the other hand, no significant difference was evident when respondents were grouped according to their age $(\rho=0.497)$, hospital connected $(\rho=0.127)$, years of experience $(\rho=0.553)$ and educational attainment $(\rho=0.169)$.

5 . There is no significant difference in the perceived leadership styles between the nurse managers and staff nurses' perception on the nurse managers leadership styles $(\rho=0.719)$.
6. As perceived by the staff nurses the leadership style of nurse managers as regard to outcomes leadership reveal that all three dimensions of outcomes leadership namely extra effort, effectiveness, and satisfaction are perceived by them to be fairly often evident in their management leadership behavior (2.92).

7. There is a significant relationship between the transformational leadership to the outcomes of leadership in terms of extra effort $(\rho=0.000)$, effectiveness $(\rho=0.000)$, and satisfaction $(\rho=0.000)$. In like manner, when nurse managers continuously display transactional leadership, the outcomes of leadership although it reveals low relationship but is increasing too in the areas of extra effort $(\rho=0.029)$ and effectiveness $(\rho=0.008)$ but no significant relationship is evident in terms of satisfaction ( $\rho=0.518)$. However, the nurse managers laissez-faire leadership has no relationship in their outcomes of leadership in terms of extra effort $(\rho=0.913)$, effectiveness $(\rho=0.155)$, and satisfaction $(\mathrm{P}=0.985)$.

\section{Discussion}

This descriptive study has provided insight into nurse managers' leadership characteristics in hospital settings in Hail City. Results indicated similar perceptions of the leadership styles of nurse managers between head nurse respondents and staff nurse respondents. This contradicts the study of [32] on nursing management leadership styles, which observed that subordinates disagree almost totally with their managers' opinion about their managerial leadership style. Both groups of respondents perceived that there was correlation between outcomes of leadership and transformational leadership styles as reflected in the results were often demonstrated. These findings imply that the nurse managers as well as the staff nurses had common perceptions that outcomes leadership and transformational leadership styles prevailed in this environment. On the one hand, [33] emphasized the importance of transformational leadership, which indicates the need for further attention to training and development of effective leadership behaviors. On the other hand, [34] claimed that transformational leadership in nursing has been associated with highly performing teams and improved patient care. Furthermore, both nurse managers and staff nurses believed that laissez-faire leadership behavior was manifested occasionally. The low scores for this leadership style indicate that it had a negative effect on desired outcomes. A nurse manager has an important role in leading the work unit as a whole. In the study by [35], nurses reported that nursing leadership was considered as being present and available in daily work, because a work unit is seen as a reflection of the nurse leader's leadership style. Additionally, [36] emphasized that leaders should encourage their employees to develop goals and plan to achieve them, thereby influencing their professional development. Nurse leaders are strongly expected to be self-motivated, to share common goals, and they must possess the internal drive to finish the job at hand because they have important roles in the administration of the nursing organization and affect people's lives and attitudes towards their profession [37]. 
Despite the lack of significant differences in the perception of leadership styles between nurse managers and staff nurses, the nurse managers scored transactional leadership style considerably lower than did the staff nurses. This finding is consistent with those of [38] and [13], which stressed that nurse managers perceived themselves as having fewer transactional behaviors than the staff nurses' perceptions. In the study conducted by [39], there was a positive association between the satisfaction levels among employees and the styles of leadership (transactional and transformational). The staff believed that there was a greater use of transactional and transformational styles of leadership by the nurse managers. [40] as well as [41] concurred with such a finding. In the present study, the staff nurses believed that their nurse managers used transformational leadership more often than other styles.

\section{Conclusion and Recommendation}

The findings of this study indicate that information about a nurse manager's perception of their own leadership style and the perception of the staff nurses on nurse managers' leadership behavior will provide directions for the continuing education and professional development of future leaders. The unanimity of the respondents' perception on the leadership style of the nurse managers gave a clear picture of the nurse manager's skills and knowledge in the use of different leadership styles because both the nurse managers and their staff nurses did evaluations. These evaluations highlight the need for head nurses to reflect more on their practices and somehow to find new ways for further enhancement of their transformational- and outcomebased leadership styles, which are believed to be most effective in bringing about positive outcomes for health care providers and patients.

\subsection{Recommendation}

In today's health care environment, there is a need to develop leadership behaviors that are proven effective in implementing positive and adaptive behaviors among nurse leaders. It is important that nurse managers be given the opportunity and training to hone their management skills further. From the results of this study, it is evident that managers need access to continued leadership training and feedback from staff nurses on their leadership behaviors.

\section{Acknowledgements}

All authors would like to the thank University of Hail (UoH) for providing funds to support this research project. Our special thanks are extended to the nursing managers and staff who participated in this research.

\section{References}

[1] Jennings BM. Work stress and burnout among nurses: Role of the work environment and working conditions. In: Hughes RG, editor. Patient Safety and Quality: An Evidence-Based Handbook for
Nurses. Rockville (MD): Agency for Healthcare Research and Quality (US); 2008 Apr. Chapter 26. Available from: http://www.ncbi.nlm.nih.gov/books/NBK2668/.

[2] Thompson, P. A. Key challenges facing American nurse leaders. Journal of Nursing Management. Nov; 16 (8):912-4.

[3] Carney, M. Understanding organizational culture: the key to successful middle manager strategic involvement in health care delivery Journal of Nursing Management 14(1), 23-33, 2006.

[4] Marquis B.L. \& C.J. Huston. Leadership roles and management functions in nursing: theory and application. 6th edn. Wolters/Kluwer/Lippincott Williams and Wilkins, Philadelphia, 2009.

[5] Roussel L, R.C. Swansburg \& R.J. Swansburg. Management and leadership for nurse administrators. 5th ed. Jones and Bartlett Publishers, Massachusetts, 2009.

[6] Sullivan E.J. \& G. Garland. Practical leadership and management in nursing. Pearson Education Limited, Harlow, 2010.

[7] Sutherland, A.M. \& F. Dodd, F. 'NHS Lanarkshire's leadership development programme's impact on clinical practice', International Journal of Health Care Quality Assurance, 21(6), pp. 569-584.

[8] McSherry R. \& P. Pearce. Clinical Governance: A guide to implementation for healthcare professionals. Oxford: WileyBlackwell Publishers, 2011.

[9] McSherry R. \& P. Pearce. What are the effective ways to translate clinical leadership into health care quality improvement? Volume 2016:8 Pages 11-17.

[10] Al-Hosis, K. Succession planning for nurse managers in Saudi Arabia (Unpublished doctoral thesis). Monash University, Melbourne, 2009.

[11] Alshammari, Farhan. Nursing leadership in the ministry of health hospitals of Saudi Arabia. Retrieved from https://researchbank.rmit.edu.au/eserv/rmit:160740, 2014.

[12] Jaffe, Robert A., "Staff nurse perception of leadership styles among nurse managers". Nursing Theses and Capstone Projects. Paper 106, 2012.

[13] McGuire E.\& S.M.Kennerly (2006). Nurse managers as transformational and transactional leaders. Nursing Economics, 24(4):179-185, 2006.

[14] Murphy, L. Transformational leadership: A cascading chain reaction. Journal of Nursing Management, 13(2), 128-136.

[15] Nielson, K., Yarker, J., Brenner, S. O., Randall, R., \& Borg, V. The importance of transformational style for the well-being of employees working with older people. Journal of Advanced Nursing, 63(5), 465-475. 2008.

[16] Spinelli, R. The applicability of Bass's model of transformational, transactional, and laissez-faire leadership in the hospital administrative environment. Hospital Topics, 84(2), 11-18, 2006.

[17] Thyer, G. Dare to be different: transformational leadership may hold the key to reducing the nursing shortage. Journal of Nursing Management 11(2), 73-79. 2003.

[18] Bass B.M. \& B. J. Avolio. Transformational leadership development: Manual for the Multifactor Leadership Questionnaire”. Palo Alto, CA: Consulting Psychologist Press, 1990.

[19] Burns, James Mac Gregor. Transforming leadership a new pursuit of happiness, Grove Press New York, 2003.

[20] Cook, M. J. The renaissance of clinical leadership. International Nursing Review. 2001.

[21] Madison, J. The value of mentoring in nursing leadership: A descriptive study. Nursing Forum. 1994.

[22] Northhouse, P. G. (2012). Introduction to leadership concepts and practice. 2nd edition. Retrieved from tps://books.goohtgle.com.sa, Oct, 2016.

[23] Sofarelli, D. \& D. Brown. The need for nursing leadership in uncertain times. Journal of Nursing Management; 6(4): 201-7, Jul, 1998.

[24] Acorn, S., P. A. Ratner, \& M. Crawford. Decentralization as a determinant of autonomy, job satisfaction, and organizational commitment among nurse managers. Nursing Research, 46 (1), 52-58, 1997.

[25] Larrabee, J.H., M. A. Janney, C.L. Ostrow, ML Withrow, G.R. Hobbs Jr. \&C. Burant, Christopher. Predicting registered nurse job satisfaction and intent to leave. Journal of Nursing Administration: Volume 33 - Issue 5 - pp 271-283, May, 2003.

[26] Laschinger, HK, J. Finegan, J. Shamian, \& P. Wilk, Impact of structural and psychological empowerment on job strain in nursing 
work settings: expanding Kanter's model. Journal of Nursing Administration. ; 31(5):260-72, May, 2001.

[27] Falk-Rafael, A.R. Empowerment as a process of evolving consciousness: A model of empowered caring. Advances in Nursing Science 24(1): 1-16, October 2001.

[28] Watson, R., A. Stimpson, A. Topping. Clinical competence assessment in nursing: a systematic review of the literature. Journal of Advanced Nursing, 39(5): 421-31, PMID: 12175351 September, 2002.

[29] Bass, B. M., \& B. J. Avolio. Improving organizational effectiveness through transformational leadership. Thousand Oaks, CA: Sage Publications, 1994.

[30] Golembiewski, Robert T. Handbook of organizational behavior 2nd ed. Revised \& Expanded p.25 Marcel Dekker Inc., 2001.

[31] http://www.wma.net/en/copyright/index.html Retrieved May, 2016.

[32] Sellgren, S.F., G. Ekvall \& G. Tomson. Leadership styles in nursing management: Preferred and perceived. Journal of Nursing Management 14(5): 348-55, August, 2006.

[33] Abualrub, R.F. \& M.G. Alghamdi. The impact of leadership styles on nurses' satisfaction and intention to stay among Saudi nurses. 2011.

[34] Fisher, S.A. Transformational leadership in nursing: a concept analysis, 2016.
[35] Rosengren, K., Athlin, E. \& Segesten, K. Presence and availability: staff conceptions of nursing leadership on an intensive care unit. Journal of Nursing Management, 15(5), 522-529, 2007.

[36] Stapleton, P. Henderson, A., Creedy, D.K., Cooke, M., Patterson, E., H. \& Dalton, M. Boosting morale and improving performance in the nursing setting. Journal of Nursing Management.15 (8), 811-816, 2007.

[37] Aboshaiqah, Ahmad E., et al. Nurses' perception of managers' leadership styles and its associated outcomes. American Journal of Nursing Research: 57-62. 2.42014.

[38] Edmunds, E. Leadership style of nurse managers in a designated magnet hospital. Walsh University. Retrieved from: https://etd.ohiolink.edu/pg_10?0::NO:10:P10_ACCESSION_NU M:walsh1398030398, 2014.

[39] Bass, M.B. \& E.G. Riggio. Transformational leadership 2nd ed. Mahwah, NJ: Lawrence Erlbaum Associates, 2006, 282 pages.

[40] Failla. K.R. \& J.F. Stichler. Manager and staff perceptions of the manager's leadership style. 2008.

[41] Khan, Omar S. The case for real change. Strategy \& Leadership, Vol. 34 Iss: 1, pp.32-35, 2006.

[42] Perez, Joseph Warren L., Impact of nurse managers' leadership styles on staff nurses' intent to turnover. Nursing Theses and Capstone Projects. Paper 31, 2014.

\section{Appendix A Results in Tables}

\section{Problem 1. Define the profiles of nurse managers and staff nurses in terms of:}
a. Age
b. Gender
c. Nationality
d. Educational attainment
e. Hospital location
f. Years of experience
g. Trainings attended
g. Salary

Table 1. Demographic Profile of the Nurse Managers and Staff Nurses

\begin{tabular}{|c|c|c|c|c|c|}
\hline \multirow{2}{*}{\multicolumn{2}{|c|}{ Demographic Profile }} & \multicolumn{2}{|c|}{ Head Nurses (38) } & \multicolumn{2}{|c|}{ Staff Nurses (196) } \\
\hline & & $\mathbf{f}$ & $\%$ & $\mathbf{f}$ & $\%$ \\
\hline \multirow{4}{*}{ Age } & $20-30$ & 21 & 55.3 & 126 & 64.3 \\
\hline & $31-40$ & 13 & 34.2 & 47 & 24 \\
\hline & $41-50$ & 2 & 5.3 & 17 & 8.7 \\
\hline & $51-64$ & 2 & 5.3 & 6 & 3.1 \\
\hline \multirow{2}{*}{ Gender } & Male & 9 & 23.7 & 25 & 12.8 \\
\hline & Female & 29 & 76.3 & 171 & 87.2 \\
\hline \multirow{2}{*}{ Nationality } & Saudi & 26 & 68.4 & 118 & 60.2 \\
\hline & Non Saudi & 12 & 31.6 & 78 & 39.8 \\
\hline \multirow{5}{*}{ Educational Attainment } & Diploma & 13 & 34.2 & 88 & 44.9 \\
\hline & Associate & 0 & 0 & 0 & 0 \\
\hline & Bachelor & 25 & 65.8 & 106 & 54.1 \\
\hline & Master & 0 & 0 & 2 & 1.0 \\
\hline & Doctorate & 0 & 0 & 0 & 0 \\
\hline \multirow{4}{*}{ Hospital Location } & Hail General Hospital & 9 & 23.7 & 39 & 19.9 \\
\hline & Maternity Hospital & 13 & 34.2 & 48 & 24.5 \\
\hline & King Khalid Hospital & 11 & 28.9 & 89 & 45.4 \\
\hline & Mental Hospital & 5 & 13.2 & 20 & 10.2 \\
\hline \multirow{3}{*}{ Years of Experience } & $1-10$ & 26 & 68.4 & 156 & 79.6 \\
\hline & $11-20$ & 10 & 26.3 & 31 & 15.8 \\
\hline & $21-30$ & 2 & 5.3 & 9 & 4.6 \\
\hline \multirow{3}{*}{ Trainings attended } & No answer & 4 & 10.5 & 0 & 0 \\
\hline & Yes & 13 & 34.2 & 31 & 15.8 \\
\hline & No & 21 & 55.3 & 165 & 84.2 \\
\hline \multirow{8}{*}{ Salary } & $1000-2000$ SR & 0 & 0 & 0 & 0 \\
\hline & $2001-3000 \mathrm{SR}$ & 0 & 0 & 0 & 0 \\
\hline & $3001-4000 \mathrm{SR}$ & 2 & 5.3 & 11 & 5.6 \\
\hline & $4001-6000$ SR & 5 & 13.2 & 53 & 27.0 \\
\hline & $6001-8000 \mathrm{SR}$ & 6 & 15.8 & 44 & 22.4 \\
\hline & $8001-10000$ SR & 7 & 18.4 & 57 & 29.1 \\
\hline & $10001-15000 \mathrm{SR}$ & 18 & 47.4 & 29 & 14.8 \\
\hline & 15001 SR above & 0 & 0 & 2 & 1.0 \\
\hline
\end{tabular}


Table 1 shows the demographic profile of the thirty eight (38) nurse manager-respondents according to age, gender, nationality, educational attainment, hospital location, years of experience and salary. The data reveal that the age range of the subjects was 20-64 with the highest percentage (55.3\%) falling between 20-30 years of age. In terms of gender, 76.3\% of the respondents were females while the remaining $23.7 \%$ were males. The table also highlights that most (68.4\%) of the participants were Saudi nationals who obtained a bachelor's degree in nursing (65.8\%). As to hospital location, many (34.2\%) respondents were employed in Maternity Hospital who held 1-10 (68.4\%) years of experience as nurse mangers. Further, a majority of the respondents indicated a no (55.3\%) response to trainings attended however, receiving a monthly salary of 10 001-15 000 SR (47.4\%).

In like manner, the table also displays the demographic profile of the staff nurse-respondents ( $\mathrm{N}=196)$ in relation to age, gender, nationality, educational attainment, hospital location, years of experience, trainings attended and salary. Participants in this study were primarily aged 20-30 years (64.3\%) dominated by females (87.2\%) who were Saudi nationals (60.2\%). The highest level of education reported by the participants is master's degree; however, most of them are holders of bachelor's degree in nursing (54.1\%). Moreover, many (45.4\%) of the respondents were employed in King Khalid Hospital and least of them were affiliated with Hail Mental Hospital (10.2\%). A greater majority of the staff nurse respondents indicated a no (84.2\%) response with respect to trainings attended and as regards to salary, most of them received a monthly compensation of 10 001-15 000 SR (65.8\%) which is similar to the salary received by head nurse respondents.

\section{Problem 2. Define the leadership styles of nurse managers as perceived by:}

a. Nurse managers themselves

b. Staff nurses

Table 2. Leadership Style of the Nurse Managers as rated by themselves and Staff Nurses

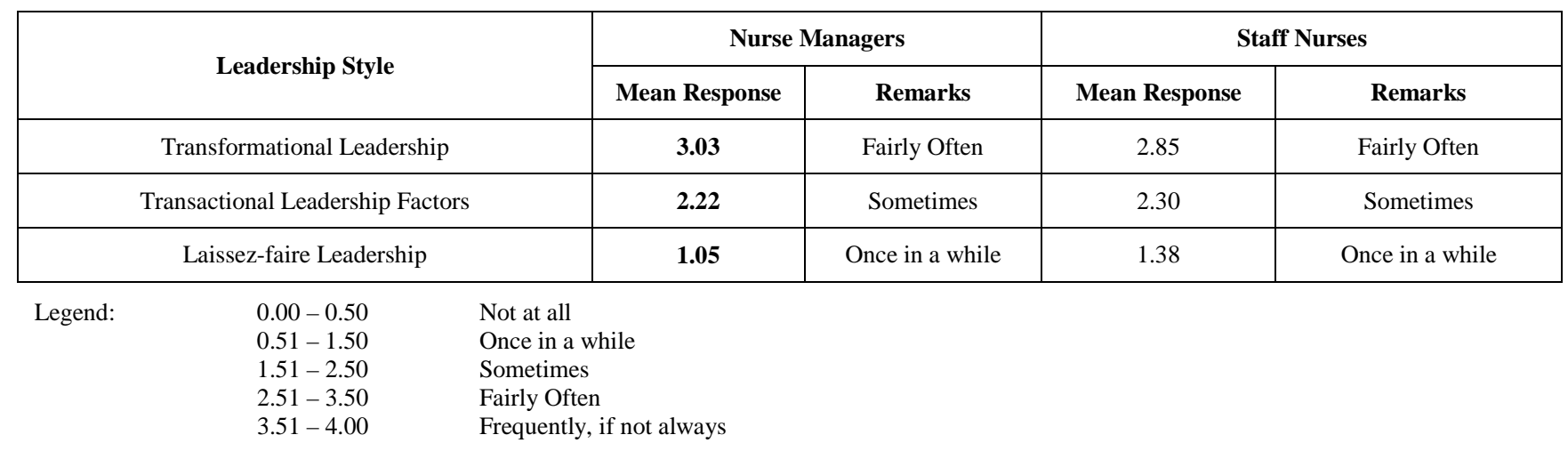

Table 2 displays the mean response of nurse managers' perception of their leadership style and perception of staff nurses on the leadership style of their nurse managers. In terms of transformational leaderships, results indicate that head nurses fairly often influenced their subordinates through employment of all five critical strategies of transformational leadership: attributed idealized influence; behavioral idealized influence; inspirational motivation; intellectual stimulation and individualized consideration (3.03). The results imply that nurse managers consistently employ transformational leadership in managing their staff. In like manner, the staff nurses' responses of "fairly often" to all dimensions reflect that they believe their superiors to be demonstrating the characteristics of a transformational leader. According to reference [42], transformational leadership is widely believed to be the most effective leadership style and utilizing this style tends to bring about positive outcomes.

Descriptive statistics of perceived leadership style of head nurses in terms of transactional leadership factors is also shown in Table 2 which include contingent reward, active management-by-exception and passive management-byexception (2.22). The results show that nurse managers perceived themselves to fairly often demonstrate contingent reward and active management by perceptions and once in a while exhibit passive management by exception. Moreover, the staff nurses also perceived that the nurse managers do sometimes display transactional leadership (2.30)

The findings on the self-evaluation of nurse managers' perception of their leadership behavior in terms of laissez-faire leadership style reveal a mean of 1.05 which indicates a once in a while manifestation where staff nurses have the same observation on the leadership style of their nurse managers in regard to laissez-faire leadership (1.38).

Overall, the data show that among the identified leadership styles of nurse managers, the respondents perceived that they fairly often displayed transformational leadership (3.03) styles. Moreover, they perceive to sometimes demonstrate transactional leadership and once in a while employ laissez-faire leadership. Staff nurses believed that they are managed by their superiors utilizing Transformational leadership (2.85) and Transactional leadership (2.30). Further, results also reveal that Laissez-faire leadership is employed by their superiors only once in a while as evaluated by the respondents. 


\section{Problem 3. Is there a significant difference in the perceived leadership style of the nurse managers when they are grouped according to their profile?}

Table 3. Difference in the Perceived Leadership Style of the Nurse Managers According to their profile

\begin{tabular}{|c|c|c|c|c|c|c|}
\hline \multicolumn{2}{|c|}{ Profile } & \multirow{2}{*}{$\frac{\text { Mean Response }}{2.95}$} & \multirow[t]{2}{*}{ F-value } & \multirow[t]{2}{*}{ P-value } & \multirow[t]{2}{*}{ Remarks } & \multirow[t]{2}{*}{ Decision on Ho } \\
\hline \multirow{4}{*}{ Age } & $20-30$ & & & & & \\
\hline & $31-40$ & 2.79 & \multirow{3}{*}{0.264} & \multirow{3}{*}{0.851} & \multirow{3}{*}{ Not Significant } & \multirow{3}{*}{ Accept Ho } \\
\hline & $41-50$ & 2.90 & & & & \\
\hline & $51-64$ & 2.90 & & & & \\
\hline \multirow{4}{*}{ Hospital } & Hail General Hospital & 2.44 & \multirow{4}{*}{5.052} & \multirow{4}{*}{0.005} & \multirow{4}{*}{ Significant } & \multirow{4}{*}{ Reject Ho } \\
\hline & Maternity Hospital & 3.12 & & & & \\
\hline & King Khalid Hospital & 3.06 & & & & \\
\hline & Mental Hospital & 2.74 & & & & \\
\hline \multirow{3}{*}{ Years of Experience } & $1-10$ & 2.94 & \multirow{3}{*}{0.602} & \multirow{3}{*}{0.553} & \multirow{3}{*}{ Not Significant } & \multirow{3}{*}{ Accept Ho } \\
\hline & $11-20$ & 2.73 & & & & \\
\hline & $21-30$ & 2.95 & & & & \\
\hline \multirow{5}{*}{ Salary } & $3001-4000 \mathrm{SR}$ & 1.93 & \multirow{5}{*}{4.647} & \multirow{5}{*}{0.004} & \multirow{5}{*}{ Significant } & \multirow{5}{*}{ Reject Ho } \\
\hline & $4001-6000 \mathrm{SR}$ & 2.80 & & & & \\
\hline & $6001-8000$ SR & 2.57 & & & & \\
\hline & $8001-10000$ SR & 3.22 & & & & \\
\hline & $10001-15000$ SR & 3.00 & & & & \\
\hline
\end{tabular}

Table 3 shows the significant difference in the perceived leadership style of the head nurses according to their profile. The results indicate that regardless of age the head nurses had the same perceived leadership styles $(\mathrm{P}=0.851)$. As regard to years of experience, the nurse managers also had the same perception on their leadership styles $(\mathrm{P}=0.553)$. However, a significant difference can be noted in the perceived leadership styles of the respondents when grouped according to hospital they were connected $(\mathrm{P}=0.005)$, and in terms of their salary $(0.004)$.

Table 4. Difference in the Perceived Leadership Styles of the Nurse Managers According to their Profile

\begin{tabular}{|c|c|c|c|c|c|c|}
\hline Profile & & Mean Response & t-value & P-value & Remarks & Decision on Ho \\
\hline Nationality & $\begin{array}{c}\text { Saudi } \\
\text { Non-Saudi }\end{array}$ & $\begin{array}{l}3.06 \\
2.53\end{array}$ & 3.362 & 0.002 & Significant & Reject Ho \\
\hline Educational Attainment & $\begin{array}{l}\text { Diploma } \\
\text { Bachelor }\end{array}$ & $\begin{array}{l}3.03 \\
2.82\end{array}$ & 1.217 & 0.232 & Not Significant & Accept Ho \\
\hline Gender & $\begin{array}{c}\text { Male } \\
\text { Female }\end{array}$ & $\begin{array}{l}2.73 \\
2.94\end{array}$ & -1.069 & 0.292 & Not Significant & Accept Ho \\
\hline Training & $\begin{array}{l}\text { Yes } \\
\text { No }\end{array}$ & $\begin{array}{l}3.05 \\
2.93\end{array}$ & 0.708 & 0.484 & Not Significant & Accept Ho \\
\hline
\end{tabular}

Shown in Table 4 is the significant difference in the perceived leadership style of the nurse managers according to their nationality, educational attainment, gender and training. The table presents a significant difference in the perceived leadership style of the respondents in terms of their nationality $(\mathrm{P}=0.002)$ while there is no significant difference in their perceived leadership style when they are clustered according to their educational attainment $(\mathrm{P}=0.232)$, gender $(\mathrm{P}=0.292)$ and on the trainings they attended $(\mathrm{P}=0.484)$. 


\section{Problem 4. Is there a significant difference in the perception of the staff nurses on the nurse managers' leadership style when they are group according to their profiles?}

Table 5. Difference in the Perception of the Staff Nurses on the Nurse Managers Leadership Styles According to their profile

\begin{tabular}{|c|c|c|c|c|c|c|}
\hline \multicolumn{2}{|c|}{ Profile } & Mean Response & F-value & P-value & Remarks & Decision on Ho \\
\hline \multirow{6}{*}{ Age } & $20-30$ & 2.89 & & & & \\
\hline & $31-40$ & 2.79 & & & & \\
\hline & & & 0.797 & 0.497 & Not Significant & Accept Ho \\
\hline & $41-50$ & 2.91 & & & & \\
\hline & $51-64$ & 2.68 & & & & \\
\hline & Hail General Hospital & 2.74 & & & & \\
\hline \multirow{5}{*}{ Hospital } & Maternity Hospital & 2.94 & & & & \\
\hline & & & 1.927 & 0.127 & Not Significant & Accept Ho \\
\hline & King Khalid Hospital & 2.90 & & & & \\
\hline & Mental Hospital & 2.71 & & & & \\
\hline & $1-10$ & 2.94 & & & & \\
\hline \multirow[t]{4}{*}{ Years of Experience } & $11-20$ & 2.73 & 0.602 & 0.553 & Not Significant & Accept Ho \\
\hline & $21-30$ & 2.95 & & & & \\
\hline & $3001-4000 \mathrm{SR}$ & 2.36 & & & & \\
\hline & $4001-6000 \mathrm{SR}$ & 2.82 & & & & \\
\hline \multirow{4}{*}{ Salary } & $6001-8000 \mathrm{SR}$ & 2.93 & & & & \\
\hline & $8001-10000$ SR & 2.97 & 3.527 & 0.005 & Significant & Reject Ho \\
\hline & $10001-15000 \mathrm{SR}$ & 2.77 & & & & \\
\hline & above 15000 SR & 3.06 & & & & \\
\hline \multirow{3}{*}{ Educational Attainment } & Diploma & 2.93 & & & & \\
\hline & Bachelor & 2.80 & 1.794 & 0.169 & Not Significant & Accept Ho \\
\hline & Master & 3.02 & & & & \\
\hline
\end{tabular}

The significant difference in the perception of the staff nurses on the head nurses' leadership style according to their profile. As depicted in Table 5, there is a significant difference in the perception of the staff nurses on their nurse managers' leadership styles when they are group according to salary received $(\mathrm{P}=0.005)$. On the other hand, no significant difference was evident when respondents were grouped according to their age $(\mathrm{P}=0.497)$, hospital employed $(\mathrm{P}=0.127)$, years of experience $(\mathrm{P}=0.553)$ and educational attainment $(\mathrm{P}=0.169)$.

Table 6. Difference in the Perception of the Staff Nurses on the Nurse Managers' Leadership Style According to their profile

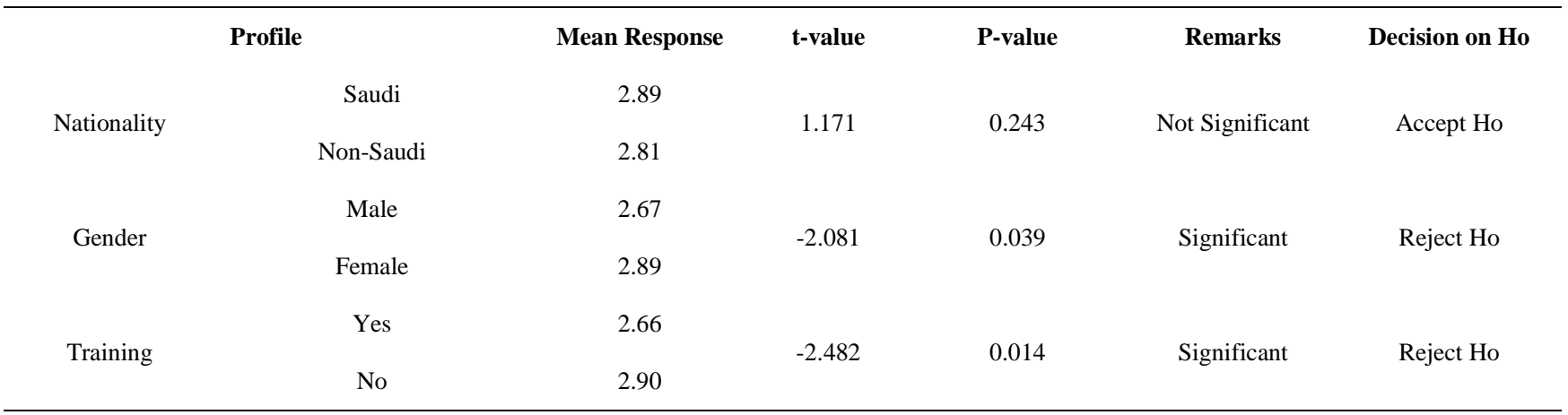

Table 6 presents the significant difference in the perception of the staff nurses on the nurse managers' leadership style in terms of nationality, gender and training. As shown in the table, there is a significant difference in term of gender $(\mathrm{P}=0.039)$ and trainings attended $(\mathrm{P}=0.014)$ while there was no significance revealed when respondents were grouped according to nationality $(\mathrm{P}=0.243)$. 
Problem 5. Is there a significant difference in the perceptions of leadership styles of the nurse managers between the staff nurses and the nurse managers themselves?

Table 7. Difference in the Perceptions of Leadership Styles of the Nurse Managers between the Staff Nurses and the Nurse Managers Themselves

\begin{tabular}{|c|c|c|c|c|c|}
\hline & Mean Response & t-value & P-value & Remarks & Decision on Ho \\
\hline Perceived Leadership Style of the Nurse Managers & 2.89 & \multirow{2}{*}{0.361} & \multirow{2}{*}{0.719} & \multirow{2}{*}{ Not Significant } & Accept Ho \\
\hline Staff Nurses' Perception on the Nurse Managers' Leadership Style & 2.86 & & & & \\
\hline
\end{tabular}

Shown in Table 7 is the significant difference in the perceived leadership style of the head nurses and staff nurses' perception on the head nurses' leadership style. As depicted in Table 7, there is no significant difference in the perceived leadership style of the nurse managers and the perception of the staff nurses on the nurse managers' leadership style $(\mathrm{P}=0.719)$.

\section{Problem 6. What are the outcomes of the nurse managers' leadership styles as perceived by the subordinates (staff nurses) in terms of:}
a. Extra effort
b. Effectiveness
c. Satisfaction

Table 8. Perception of the Staff Nurses on the Outcomes Leadership Style of the Nurse Managers

\begin{tabular}{|c|c|c|c|}
\hline \multicolumn{2}{|r|}{ Outcomes } & Mean Response & Remarks \\
\hline \multirow{4}{*}{ Extra Effort } & Gets me to do more than I am expected to do & 2.66 & Fairly Often \\
\hline & Heightens my desire to succeed & 2.95 & Fairly Often \\
\hline & Increases my willingness to try harder & 3.02 & Fairly Often \\
\hline & Grand Mean & 2.88 & Fairly Often \\
\hline \multirow{4}{*}{ Effectiveness } & Is effective in meeting my job-related needs & 2.93 & Fairly Often \\
\hline & Is effective in representing me to higher authority & 2.70 & Fairly Often \\
\hline & Is effective in meeting organizational requirements & 2.98 & Fairly Often \\
\hline & Leads a group that is effective & 3.08 & Fairly Often \\
\hline & Grand Mean & 2.92 & Fairly Often \\
\hline \multirow{3}{*}{ Satisfaction } & Uses methods of leadership that are satisfying & 2.96 & Fairly Often \\
\hline & Works with me in a satisfactory way & 2.95 & Fairly Often \\
\hline & Grand Mean & 2.96 & Fairly Often \\
\hline
\end{tabular}

As perceived by the staff nurses the leadership style of nurse managers as regard to outcomes leadership reveal that all three dimensions of outcomes leadership namely extra effort, effectiveness, and satisfaction are perceived by them to be fairly often evident in their management leadership behavior (2.92).

\section{Problem 7. Is there a significant relationship between the perceived leadership styles of the nurse managers and its outcomes of leadership?}

Table 9. Relationship of the Perceived Leadership Styles between the Nurse Managers and its Outcomes of Leadership

\begin{tabular}{|c|c|c|c|c|c|c|}
\hline $\begin{array}{c}\text { Leadership Styles } \\
\text { (x-variable) }\end{array}$ & $\begin{array}{c}\text { Outcomes Leadership } \\
\text { (y-variable) }\end{array}$ & r-value & Interpretation & P-value & Remarks & Decision on Ho \\
\hline \multirow{3}{*}{ Transformational Leadership } & Extra Effort & $0.623^{* *}$ & Moderate relationship & 0.000 & Significant & Reject Ho \\
\cline { 2 - 7 } & Effectiveness & $0.738^{* *}$ & Moderate relationship & 0.000 & Significant & Reject Ho \\
\cline { 2 - 7 } & Satisfaction & $0.699^{* *}$ & Moderate relationship & 0.000 & Significant & Reject Ho \\
\hline \multirow{3}{*}{ Transactional Leadership } & Extra Effort & $0.354^{*}$ & Low relationship & 0.029 & Significant & Reject Ho \\
\cline { 2 - 8 } & Effectiveness & $0.423^{* *}$ & Low relationship & 0.008 & Significant & Reject Ho \\
\cline { 2 - 8 } & Satisfaction & 0.188 & Negligible Relationship & 0.518 & Not Significant & Accept Ho \\
\hline \multirow{3}{*}{ Laissez-faire Leadership } & Extra Effort & 0.018 & Negligible Relationship & 0.913 & Not Significant & Accept Ho \\
\cline { 2 - 7 } & Effectiveness & 0.235 & Negligible Relationship & 0.155 & Not Significant & Accept Ho \\
\cline { 2 - 7 } & Satisfaction & -0.003 & Negligible Relationship & 0.985 & Not Significant & Accept Ho \\
\hline
\end{tabular}

**. Correlation is significant at the 0.01 level (2-tailed).

*. Correlation is significant at the 0.05 level (2-tailed). 
Table 9 shows the significant relationship between the perceived leadership styles of the nurse managers and its outcomes of leadership. As reflected in the table, there is a significant relationship between the transformational leadership to the outcomes of leadership in terms of extra effort $(\mathrm{P}=0.000)$, effectiveness $(\mathrm{P}=0.000)$, and satisfaction $(\mathrm{P}=0.000)$. This implies that as the nurse managers' exhibit transformational leadership to their staff, the outcomes of leadership moderately increases. In like manner, when nurse managers continuously display transactional leadership, the outcomes of leadership although it reveals low relationship but is increasing too in the areas of extra effort $(\mathrm{P}=0.029)$ and effectiveness $(\mathrm{P}=0.008)$ but no significant relationship is evident in terms of satisfaction $(\mathrm{P}=0.518)$.

However, when the perceived nurse managers' leadership style was related to the outcomes of leadership, it resulted to $\mathrm{P}$-values greater than the level of significance. It can be inferred that the nurse managers laissez-faire leadership has no relationship in their outcomes of leadership in terms of extra effort $(\mathrm{P}=0.913)$, effectiveness $(\mathrm{P}=0.155)$, and satisfaction $(\mathrm{P}=0.985)$. 